\title{
Surveillance to Track Progress Toward Polio Eradication - Worldwide, 2019-2020
}

\begin{abstract}
Jude N. Tuma, $\mathrm{PhD}^{1}$; Amanda L. Wilkinson, $\mathrm{PhD}^{2}$; Ousmane M. Diop, $\mathrm{PhD}^{1}$; Jaume Jorba, $\mathrm{PhD}^{3}$; Tracie Gardner, $\mathrm{PhD}^{1}$;
\end{abstract} Cynthia J. Snider, $\mathrm{PhD}^{2}$; Abhijeet Anand, MBBS${ }^{2}$; Jamal Ahmed, $\mathrm{MD}^{1}$

When the Global Polio Eradication Initiative (GPEI) was established in 1988, an estimated 350,000 poliomyelitis cases were reported worldwide. In 2020, 140 wild poliovirus (WPV) cases were confirmed, representing a $99.99 \%$ reduction since 1988. WPV type 1 transmission remains endemic in only two countries (Pakistan and Afghanistan), but outbreaks of circulating vaccine-derived poliovirus (cVDPV) occurred in 33 countries during 2019-2020 $(1,2)$. Poliovirus transmission is detected primarily through syndromic surveillance for acute flaccid paralysis (AFP) among children aged $<15$ years, with confirmation by laboratory testing of stool specimens. Environmental surveillance supplements AFP surveillance and plays an increasingly important role in detecting poliovirus transmission. Within 2 weeks of COVID-19 being declared a global pandemic (3), GPEI recommended continuing surveillance activities with caution and paused all polio supplementary immunization activities (4). This report summarizes surveillance performance indicators for 2019 and 2020 in 42 priority countries at high risk for poliovirus transmission and updates previous reports (5). In 2020, 48\% of priority countries* in the African Region, 90\% in the Eastern Mediterranean Region, and $40 \%$ in other regions met AFP surveillance performance indicators nationally. The number of priority countries rose from 40 in 2019 to 42 in 2020. ${ }^{\dagger}$ Analysis of 2019-2020 AFP surveillance data from 42 countries at high risk for poliovirus transmission indicates that national and subnational nonpolio AFP rates and stool specimen adequacy declined in many priority countries, particularly in the African Region, suggesting a decline in surveillance sensitivity and quality. The findings in this report can be used to guide improvements to restore a sensitive surveillance system that can track poliovirus transmission and provide evidence of interruption of transmission.

\footnotetext{
*2020 priority countries: African Region: Angola, Benin, Burkina Faso, Cameroon, Central African Republic, Chad, Congo, Côte d'Ivoire, Democratic Republic of the Congo, Eritrea, Ethiopia, Ghana, Guinea, Kenya, Liberia, Madagascar, Mali, Mauritania, Mozambique, Niger, Nigeria, Senegal, Sierra Leone, South Sudan, Togo, and Zambia; Eastern Mediterranean Region: Afghanistan, Egypt, Iran, Iraq, Libya, Pakistan, Somalia, Sudan, Syria, and Yemen; European Region: Tajikistan and Uzbekistan; South-East Asia Region: Burma (Myanmar); Western Pacific Region: Malaysia and Philippines.

$\dagger$ Countries for this report (2019-2020) were selected according to whether they had endemic transmission, had $\geq 1 \mathrm{cVDPV}$ isolate from AFP or environmental surveillance, or were deemed to be programmatically at high risk.
}

\section{Acute Flaccid Paralysis Surveillance}

Two key performance indicators assess AFP surveillance quality: the nonpolio AFP (NPAFP) rate ${ }^{\S}$ and the collection of adequate stool specimens from AFP patients. Based on the background incidence of other acute flaccid paralytic illnesses, an NPAFP rate $\geq 2$ per 100,000 children aged $<15$ years indicates that a system is sufficiently sensitive to detect circulating poliovirus. Surveillance quality is assured by collection of adequate stool specimens from $\geq 80 \%$ of persons with AFP.9

Surveillance performance in 42 priority countries that had recent WPV or cVDPV transmission or that were deemed at high risk for poliovirus transmission were reviewed. In the World Health Organization (WHO) African Region (AFR), the percentage of priority countries that met targets for both national NPAFP rate and stool adequacy indicators was $67 \%$ in 2019 and 48\% in 2020 (Table 1). Both surveillance indicator targets were met in $61 \%$ of first subnational administrative level areas (e.g., state or province) in 2019 and 53\% in 2020 (Figure). Either cVDPV2 cases or environmental isolates were detected in 14 AFR countries in 2019 and in 21 countries in 2020 (Table 1).

All 10 of the assessed priority WHO Eastern Mediterranean Region (EMR) countries met targets for both indicators in 2019, and all but one (Yemen, with stool adequacy of 78\%) did so in 2020. Subnational surveillance performance remained high in most EMR countries, but gaps were apparent in Yemen and Libya, where $44 \%$ and $53 \%$ of the population, respectively, lived in areas that met both surveillance indicator targets in 2020 (Figure). From 2019 to 2020, the number of WPV1 cases declined in the region; cVDPV2 cases increased in Afghanistan (from none to 308), Pakistan (from 22 to 135), Somalia (from three to 14), and Sudan (from none to 58); and in Yemen, significantly more cVDPV1 cases were confirmed in 2020 (31) than in 2019 (one).

In the WHO European Region (EUR), surveillance performance was assessed in the two priority countries of Tajikistan

\footnotetext{
$\$$ The number of NPAFP cases per 100,000 children aged $<15$ years.

Two stool specimens collected $\geq 24$ hours apart and within 14 days of paralysis onset, and arrival at a WHO-accredited laboratory by reverse cold chain (storing and transporting samples at recommended temperatures from the point of collection to the laboratory) and in good condition (i.e., without leakage or desiccation).
} 
TABLE 1. National and subnational acute flaccid paralysis surveillance performance indicators and number of confirmed wild poliovirus and circulating vaccine-derived poliovirus cases, by country - 42 priority countries, World Health Organization African, Eastern Mediterranean, European, South-East Asia, and Western Pacific regions, 2019-2020*

\begin{tabular}{|c|c|c|c|c|c|c|c|c|}
\hline $\begin{array}{l}\text { Year/WHO region/ } \\
\text { Country }\end{array}$ & $\begin{array}{l}\text { No. of AFP } \\
\text { cases (all } \\
\text { ages) }\end{array}$ & $\begin{array}{c}\text { Regional/ } \\
\text { National } \\
\text { NPAFP rate }\end{array}$ & $\begin{array}{l}\text { \% Subnational } \\
\text { areas with } \\
\text { NPAFP rate } \geq 2^{\S}\end{array}$ & $\begin{array}{c}\text { \% Regional or } \\
\text { national AFP } \\
\text { cases with } \\
\text { adequate } \\
\text { specimens }\end{array}$ & $\begin{array}{l}\% \text { Subnational } \\
\text { areas with } \\
\geq 80 \% \text { adequate } \\
\text { specimens }\end{array}$ & $\begin{array}{l}\% \text { Population } \\
\text { living in areas } \\
\text { meeting both } \\
\text { indicators }\end{array}$ & $\begin{array}{c}\text { No. of } \\
\text { confirmed } \\
\text { WPV cases }\end{array}$ & $\begin{array}{c}\text { No. of } \\
\text { confirmed } \\
\text { cVDPV cases }{ }^{\dagger+}\end{array}$ \\
\hline \multicolumn{9}{|l|}{2019} \\
\hline African Region & 21,234 & 5.8 & N/A & 84.0 & N/A & N/A & —§§ & 328 \\
\hline Angola & 578 & 2.8 & 66.7 & 74.4 & 38.9 & 14.7 & - & 138 \\
\hline Benin & 310 & 6.0 & 100.0 & 90.6 & 83.3 & 84.9 & - & 8 \\
\hline Burkina Faso & 374 & 4.1 & 69.2 & 82.4 & 84.6 & 65.6 & - & 1 \\
\hline Cameroon & 613 & 5.7 & 80.0 & 79.8 & 50.0 & 35.9 & - & - \\
\hline Central African Republic & 230 & 8.2 & 100.0 & 51.7 & 0.0 & 0.0 & - & 21 \\
\hline Chad & 821 & 11.0 & 95.7 & 82.8 & 56.5 & 68.1 & - & 11 \\
\hline Congo & 195 & 8.0 & 100.0 & 81.0 & 58.3 & 61.9 & - & - \\
\hline Côte d'Ivoire & 420 & 3.8 & 95.0 & 78.3 & 50.0 & 48.0 & - & - \\
\hline $\begin{array}{l}\text { Democratic Republic } \\
\text { of the Congo }\end{array}$ & 3,808 & 8.9 & 100.0 & 70.6 & 7.7 & 7.7 & - & 88 \\
\hline Eritrea & 110 & 5.0 & 83.3 & 100.0 & 83.3 & 73.5 & - & - \\
\hline Ethiopia & 1,222 & 2.7 & 100.0 & 85.3 & 90.9 & 99.6 & - & 14 \\
\hline Ghana & 648 & 5.2 & 100.0 & 87.5 & 93.8 & 96.4 & - & 18 \\
\hline Guinea & 233 & 4.1 & 100.0 & 87.6 & 62.5 & 59.6 & - & - \\
\hline Guinea-Bissau & 44 & 5.1 & 100.0 & 86.4 & 77.8 & 70.5 & - & - \\
\hline Kenya & 560 & 2.6 & 72.3 & 92.9 & 78.7 & 66.9 & - & - \\
\hline Liberia & 70 & 3.3 & 86.7 & 91.4 & 80.0 & 81.7 & - & - \\
\hline Madagascar & 613 & 5.6 & 100.0 & 93.0 & 86.4 & 91.9 & - & - \\
\hline Mali & 301 & 3.2 & 90.9 & 82.1 & 63.6 & 77.8 & - & - \\
\hline Mauritania & 55 & 3.0 & 86.7 & 85.5 & 73.3 & 59.7 & - & - \\
\hline Mozambique & 513 & 3.6 & 100.0 & 72.3 & 27.3 & 31.5 & - & - \\
\hline Niger & 906 & 7.7 & 100.0 & 67.7 & 0.0 & 0.0 & - & 1 \\
\hline Nigeria & 7,509 & 8.5 & 100.0 & 94.1 & 100.0 & 100.0 & - & 18 \\
\hline Senegal & 183 & 2.4 & 64.3 & 80.9 & 57.1 & 46.7 & - & - \\
\hline Sierra Leone & 123 & 3.7 & 100.0 & 78.9 & 50.0 & 43.5 & - & - \\
\hline South Sudan & 399 & 7.0 & 100.0 & 89.0 & 90.0 & 84.0 & - & - \\
\hline Togo & 164 & 4.5 & 100.0 & 68.9 & 50.0 & 52.2 & - & 8 \\
\hline Zambia & 232 & 2.8 & 70.0 & 81.9 & 70.0 & 36.8 & - & 2 \\
\hline $\begin{array}{l}\text { Eastern Mediterranean } \\
\text { Region }\end{array}$ & 24,788 & 12.3 & N/A & 89.2 & N/A & N/A & 176 & 26 \\
\hline Afghanistan & 3,768 & 23.9 & 100.0 & 93.8 & 100.0 & 100.0 & 29 & - \\
\hline Egypt & 1,343 & 4.0 & 92.6 & 93.4 & 88.9 & 85.0 & - & - \\
\hline Iran & 1,070 & 5.5 & 96.8 & 97.0 & 96.8 & 98.9 & - & - \\
\hline Iraq & 1,157 & 7.1 & 100.0 & 94.3 & 100.0 & 100.0 & - & - \\
\hline Libya & 107 & 5.9 & 85.7 & 98.1 & 100.0 & 91.9 & - & - \\
\hline Pakistan & 15,218 & 21.3 & 100.0 & 86.6 & 100.0 & 100.0 & 147 & 22 \\
\hline Somalia & 361 & 5.0 & 100.0 & 95.6 & 100.0 & 100.0 & - & 3 \\
\hline Sudan & 608 & 3.6 & 100.0 & 96.4 & 100.0 & 100.0 & - & - \\
\hline Syria & 377 & 5.8 & 85.7 & 85.4 & 71.4 & 65.1 & - & - \\
\hline Yemen & 779 & 6.7 & 100.0 & 85.8 & 95.7 & 97.5 & - & 1 \\
\hline European Region & 226 & 1.7 & N/A & 98.2 & N/A & N/A & - & - \\
\hline Tajikistan & 92 & 2.7 & 100.0 & 95.7 & 100.0 & 100.0 & - & - \\
\hline Uzbekistan & 134 & 1.4 & 14.3 & 100.0 & 100.0 & 9.5 & - & - \\
\hline South-East Asia Region & 420 & 3.0 & N/A & 90.2 & N/A & N/A & - & 6 \\
\hline Burma (Myanmar) & 420 & 3.0 & 83.3 & 90.2 & 83.3 & 77.0 & - & 6 \\
\hline Western Pacific Region & 1,075 & 2.5 & N/A & 51.6 & N/A & N/A & - & 17 \\
\hline Malaysia & 183 & 2.3 & 64.3 & 74.3 & 42.9 & 27.9 & - & 3 \\
\hline Philippines & 892 & 2.5 & 25.0 & 47.0 & 0.0 & 0.0 & - & 14 \\
\hline \multicolumn{9}{|l|}{2020} \\
\hline African Region & 20,181 & 5.4 & N/A & 85.2 & N/A & N/A & - & 532 \\
\hline Angola & 383 & 2.4 & 77.8 & 82.0 & 61.1 & 37.3 & - & 3 \\
\hline Benin & 277 & 5.4 & 100.0 & 88.1 & 91.7 & 94.5 & - & 3 \\
\hline Burkina Faso & 1,178 & 11.9 & 100.0 & 86.1 & 92.3 & 95.2 & - & 61 \\
\hline Cameroon & 605 & 5.4 & 100.0 & 77.9 & 50.0 & 40.3 & - & 7 \\
\hline Central African Republic & 222 & 9.8 & 100.0 & 64.4 & 28.6 & 28.2 & - & 4 \\
\hline
\end{tabular}

See table footnotes on the next page. 
TABLE 1. (Continued) National and subnational acute flaccid paralysis surveillance performance indicators and number of confirmed wild poliovirus and circulating vaccine-derived poliovirus cases, by country - 42 priority countries, World Health Organization African, Eastern Mediterranean, European, South-East Asia, and Western Pacific regions, 2019-2020*

\begin{tabular}{|c|c|c|c|c|c|c|c|c|}
\hline $\begin{array}{l}\text { Year/WHO region/ } \\
\text { Country }\end{array}$ & $\begin{array}{l}\text { No. of AFP } \\
\text { cases (all } \\
\text { ages) }\end{array}$ & $\begin{array}{c}\text { Regional/ } \\
\text { National } \\
\text { NPAFP rate }\end{array}$ & $\begin{array}{l}\% \text { Subnational } \\
\text { areas with } \\
\text { NPAFP rate } \geq 2 \S\end{array}$ & $\begin{array}{l}\text { \% Regional or } \\
\text { national AFP } \\
\text { cases with } \\
\text { adequate } \\
\text { specimens }\end{array}$ & $\begin{array}{l}\% \text { Subnational } \\
\text { areas with } \\
\geq 80 \% \text { adequate } \\
\text { specimens }\end{array}$ & $\begin{array}{l}\% \text { Population } \\
\text { living in areas } \\
\text { meeting both } \\
\text { indicators** }\end{array}$ & $\begin{array}{c}\text { No. of } \\
\text { confirmed } \\
\text { WPV cases }\end{array}$ & $\begin{array}{c}\text { No. of } \\
\text { confirmed } \\
\text { cVDPV cases }\end{array}$ \\
\hline$\overline{\text { Chad }}$ & 990 & 11.7 & 95.7 & 81.4 & 65.2 & 69.0 & - & 99 \\
\hline Congo & 93 & 3.7 & 66.7 & 83.9 & 66.7 & 31.7 & - & 2 \\
\hline Côte d'Ivoire & 742 & 6.0 & 100.0 & 74.5 & 39.4 & 32.6 & - & 60 \\
\hline $\begin{array}{l}\text { Democratic Republic } \\
\text { of the Congo }\end{array}$ & 3,303 & 7.6 & 100.0 & 81.0 & 53.8 & 55.9 & - & 81 \\
\hline Eritrea & 156 & 7.0 & 66.7 & 99.4 & 66.7 & 61.2 & - & - \\
\hline Ethiopia & 1,341 & 2.9 & 81.8 & 86.4 & 81.8 & 91.5 & - & 26 \\
\hline Ghana & 709 & 5.9 & 100.0 & 85.9 & 81.2 & 78.7 & - & 12 \\
\hline Guinea & 321 & 4.6 & 100.0 & 70.1 & 25.0 & 16.4 & - & 44 \\
\hline Guinea-Bissau & 21 & 2.6 & 45.5 & 52.4 & 9.1 & 13.8 & - & - \\
\hline Kenya & 336 & 1.6 & 29.8 & 86.9 & 70.2 & 17.4 & - & - \\
\hline Liberia & 48 & 2.3 & 73.3 & 95.8 & 100.0 & 64.8 & - & - \\
\hline Madagascar & 635 & 5.7 & 100.0 & 90.4 & 95.5 & 96.4 & - & - \\
\hline Mali & 375 & 3.4 & 90.9 & 76.0 & 45.5 & 59.9 & - & 45 \\
\hline Mauritania & 17 & 0.9 & 26.7 & 64.7 & 13.3 & 0.0 & - & - \\
\hline Mozambique & 374 & 2.6 & 72.7 & 73.5 & 36.4 & 14.6 & - & - \\
\hline Niger & 585 & 4.8 & 100.0 & 72.0 & 25.0 & 24.1 & - & 9 \\
\hline Nigeria & 6,330 & 7.0 & 97.3 & 94.5 & 97.3 & 97.8 & - & 8 \\
\hline Senegal & 135 & 1.7 & 50.0 & 77.0 & 28.6 & 12.2 & - & - \\
\hline Sierra Leone & 115 & 3.2 & 80.0 & 78.3 & 40.0 & 19.3 & - & 9 \\
\hline South Sudan & 434 & 6.4 & 100.0 & 80.4 & 70.0 & 64.3 & - & 50 \\
\hline Togo & 161 & 4.0 & 100.0 & 62.1 & 0.0 & 0.0 & - & 9 \\
\hline Zambia & 295 & 3.6 & 80.0 & 69.8 & 10.0 & 8.5 & - & - \\
\hline $\begin{array}{l}\text { Eastern Mediterranean } \\
\text { Region }\end{array}$ & 20,418 & 9.7 & N/A & 87.7 & $\mathrm{~N} / \mathrm{A}$ & $N / A$ & 140 & 546 \\
\hline Afghanistan & 3,972 & 22.9 & 100.0 & 91.9 & 97.1 & 98.4 & 56 & 308 \\
\hline Egypt & 1,009 & 3.0 & 85.2 & 94.5 & 92.6 & 93.8 & - & - \\
\hline Iran & 618 & 3.2 & 87.1 & 98.5 & 96.8 & 91.2 & - & - \\
\hline Iraq & 476 & 2.9 & 84.2 & 93.3 & 94.7 & 89.0 & - & - \\
\hline Libya & 95 & 5.1 & 71.4 & 98.9 & 100.0 & 52.9 & - & - \\
\hline Pakistan & 11,969 & 16.4 & 100.0 & 85.1 & 100.0 & 100.0 & 84 & 135 \\
\hline Somalia & 378 & 4.9 & 85.7 & 94.2 & 81.0 & 94.8 & - & 14 \\
\hline Sudan & 733 & 3.9 & 100.0 & 92.8 & 94.4 & 93.6 & - & 58 \\
\hline Syria & 343 & 5.3 & 92.9 & 84.5 & 78.6 & 63.6 & - & - \\
\hline Yemen & 825 & 6.8 & 95.7 & 77.8 & 56.5 & 43.8 & - & 31 \\
\hline European Region & 138 & 1.0 & $N / A$ & 95.7 & $\mathrm{~N} / \mathrm{A}$ & $\mathrm{N} / \mathrm{A}$ & - & 1 \\
\hline Tajikistan & 83 & 2.4 & 50.0 & 92.8 & 100.0 & 30.6 & - & 1 \\
\hline Uzbekistan & 55 & 0.5 & 0.0 & 100.0 & 92.9 & 0.0 & - & - \\
\hline South-East Asia Region & 186 & 1.3 & N/A & 85.5 & $\mathrm{~N} / \mathrm{A}$ & $N / A$ & - & - \\
\hline Burma (Myanmar) & 186 & 1.3 & 22.2 & 85.5 & 72.2 & 9.0 & - & - \\
\hline Western Pacific Region & 980 & 2.3 & $\mathrm{~N} / \mathrm{A}$ & 65.3 & N/A & N/A & - & 2 \\
\hline Malaysia & 157 & 2.0 & 37.5 & 81.5 & 62.5 & 22.9 & - & 1 \\
\hline Philippines & 823 & 2.4 & 5.9 & 62.2 & 5.9 & 2.0 & - & 1 \\
\hline
\end{tabular}

Abbreviations: AFP = acute flaccid paralysis; $\mathrm{CVDPV}=$ circulating vaccine-derived poliovirus; N/A = not applicable; NPAFP = nonpolio AFP; WHO = World Health Organization; WPV = wild poliovirus.

* Data as of April 16, 2021.

† Per 100,000 persons aged $<15$ years per year.

$\S$ For all subnational areas regardless of population size.

I Standard WHO target is adequate stool specimen collection from $\geq 80 \%$ of AFP cases, assessed by timeliness and condition. For this analysis, timeliness was defined as two specimens collected $\geq 24$ hours apart ( $\geq 1$ calendar day in this data set), both within 14 days of paralysis onset. Good condition was defined as arrival of specimens in a WHO-accredited laboratory with reverse cold chain maintained and without leakage or desiccation.

** Percentage of the country's population living in subnational areas that met both surveillance indicators (NPAFP rates $\geq 2$ per 100,000 persons aged $<15$ years per year and $\geq 80 \%$ of AFP cases with adequate specimens).

++ CVDPV was associated with at least one case of AFP with evidence of community transmission and genetically linked. Guidelines for classification of cVDPV are available. https://polioeradication.org/wp-content/uploads/2016/09/Reporting-and-Classification-of-VDPVs_Aug2016_EN.pdf

$\S \S$ Dashes indicate that no confirmed cases were found.

ๆๆ For this country, MMWR uses the U.S. State Department short-form name "Burma"; WHO uses "Myanmar." 
FIGURE. Combined performance indicators for the quality of acute flaccid paralysis surveillance* in subnational areas of 42 priority countries ${ }^{\dagger}-$ World Health Organization African, Eastern Mediterranean, South-East Asia, and Western Pacific regions, 2020

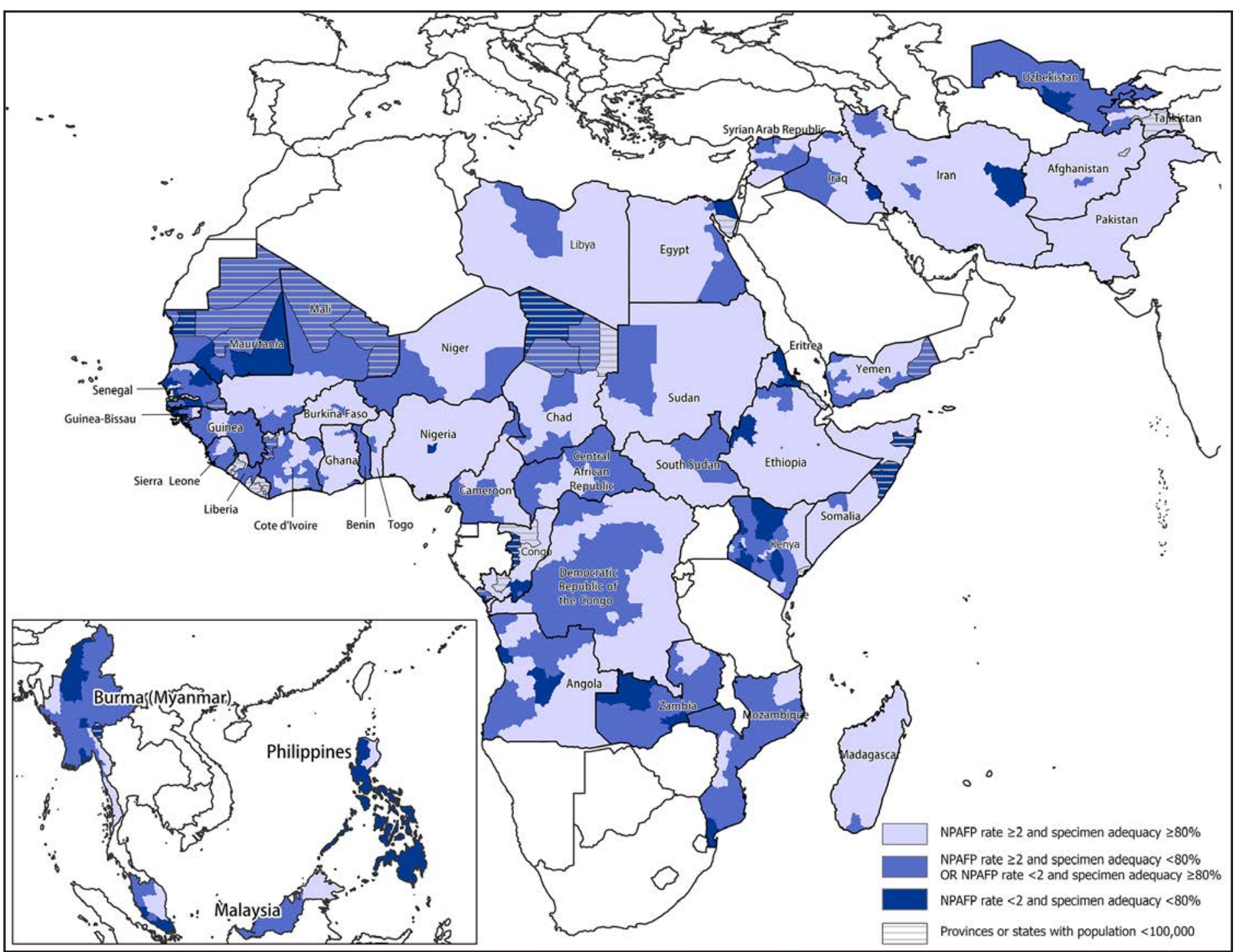

Abbreviations: AFP $=$ acute flaccid paralysis; NPAFP $=$ nonpolio AFP; WHO $=$ World Health Organization.

* Targets: two or more NPAFP cases per 100,000 children aged $<15$ years per year and $\geq 80 \%$ of persons with AFP having two stool specimens collected $\geq 24$ hours apart within 14 days of paralysis onset and arrival of these specimens at a WHO-accredited laboratory by reverse cold chain and in good condition.

† For Burma (Myanmar), MMWR uses the U.S. State Department short-form name "Burma"; WHO uses "Myanmar."

and Uzbekistan. In 2019 and 2020, only Tajikistan met both surveillance indicator targets at the national level. In both years, Uzbekistan met only the stool adequacy indicator target. Subnational surveillance performance was poor in both countries in 2020 (Figure); in Uzbekistan, no subnational area met both surveillance indicator targets. One cVDPV2 case was detected in Tajikistan in 2020, and the subsequent outbreak resulting from this case continues in 2021.

Surveillance performance was assessed in Burma (Myanmar), ${ }^{* *}$ the single priority country in the WHO

\footnotetext{
** For this country, $M M W R$ uses the U.S. State Department short-form name "Burma"; WHO uses "Myanmar."
}

South-East Asia Region (SEAR), where, at the national level, both surveillance indicator targets were met in 2019 and only stool adequacy was met in 2020. Subnational surveillance performance declined from 2019 to 2020 ; in $2019,77 \%$ of the population lived in areas that met both surveillance indicator targets whereas in 2020 only $9 \%$ lived in areas that met both surveillance targets.

In the WHO Western Pacific Region (WPR), surveillance performance was assessed in Malaysia and Philippines. Both countries met the NPAFP indicator target in 2019 and 2020, and neither met the stool adequacy indicator in 2019; however, Malaysia did meet the stool adequacy indicator in 2020. 
During 2019-2020, approximately one quarter of Malaysia's population and $<3 \%$ of Philippines' population lived in areas that met both indicator targets (Figure); cVDPV1 cases occurred in both countries in 2019, and one case occurred in Malaysia in 2020. Philippines reported cVDPV2 cases in both 2019 and 2020.

Genomic sequence analysis identified $41 \mathrm{cVDPV}$ emergences from AFP cases (39 type 2 cVDPV emergences) in 18 countries in 2019 and 34 cVDPV emergences (32 type 2 cVDPV emergences) in 25 countries in 2020. More than one half (22 of 41) of cVDPV emergences detected in 2019 continued to be detected during 2020 .

\section{Environmental Surveillance}

Environmental surveillance is the systematic testing of sewage samples to identify populations shedding polioviruses; environmental surveillance in some locations, might be more sensitive to detection of poliovirus transmission than AFP surveillance, given that paralysis occurs in $<1 \%$ of poliovirus infections (G). During 2019-2020, poliovirus was isolated in a sewage sample before (or in the absence of) a confirmed AFP case in Afghanistan, Cameroon, Chad, Côte d'Ivoire, Egypt, Ghana, Iran, Kenya, Liberia, Senegal (all cVDPV2), Philippines (cVDPV1), and Malaysia (cVDPV1 and cVDPV2).

In Nigeria, the number of cVDPV2 isolations declined from 104 isolates collected from 22 environmental sites in 2019 to 11 isolates collected from three sites in 2020. In Afghanistan and Pakistan, the number of cVDPV2 detections increased from 56 isolates in 2019 (all in Pakistan) to 599 isolates (57\% in Afghanistan) resulting from two 2019 cVDPV2 emergences and seven additional new cVDPV2 emergences in 2020.

In 2019, 10 WPV 1 genetic clusters (isolates with $\geq 95 \%$ genetic relatedness) were detected in environmental sites from four provinces in Afghanistan and four provinces in Pakistan (7). During the reporting period, $30 \mathrm{cVDPV}$ emergences (29 cVDPV2 and one cVDPV1) were detected in sewage samples collected in 26 countries (12 countries in 2019 and 24 countries in 2020).

\section{Global Polio Laboratory Network}

The WHO Global Polio Laboratory Network (GPLN) is an essential component of poliovirus surveillance. It comprises 145 quality-assured poliovirus laboratories in the six WHO regions. GPLN laboratories implement standardized protocols to 1) isolate polioviruses (all laboratories); 2) conduct intratypic differentiation to identify WPV, Sabin (oral polio vaccine) polioviruses, and VDPV (134 laboratories); and 3) conduct genomic sequencing (28 laboratories). Poliovirus transmission pathways are monitored through sequence analysis of the capsid protein (VP1) coding region from isolates. The accuracy and quality of testing at GPLN laboratories are monitored through an annual accreditation program of on-site reviews and proficiency testing (8). For laboratories conducting environmental surveillance, another accreditation checklist with separate timeliness indicators is used.

GPLN tested 219,049 stool specimens in 2019 and 147,582 in 2020 (Table 2), and cVDPVs were isolated from 437 AFP cases in 2019 and from 1,067 in 2020. From 2019 to 2020, the number of cVDPV isolates increased from 303 to 530 in AFR, from 50 to 533 in EMR, and from zero to two in EUR; the number decreased from 10 to zero in SEA and from 74 to two in WPR. In 2019 and 2020, all regions met the timeliness indicator for poliovirus isolation.

The South Asia genotype (the only WPV1 genotype detected globally since 2016) was detected in Afghanistan and Pakistan in 2019 (176 cases) and 2020 (140 cases). Orphan isolates (those with $\leq 98.5 \%$ genetic identity in VP1, compared with other isolates) indicate possible gaps in AFP surveillance; in 2019, orphan isolates accounted for five of 176 (3\%) WPV1 isolates from AFP patients (two in Afghanistan and three in Pakistan) and in 2020 for 18 of 140 (13\%) (11 in Afghanistan and seven in Pakistan).

\section{Discussion}

From 2019 to 2020, national NPAFP rates and stool adequacy declined overall in priority countries; subnational surveillance performance declined overall except for WPR countries. Although the total number of WPV1 cases decreased globally from 2019 to 2020, the increase in orphan WPV1 isolates between 2019 and 2020 in both countries suggests gaps in AFP surveillance. The COVID-19 pandemic substantially affected polio eradication activities in 2020 (9). In most AFR countries, polio surveillance field and laboratory staff were reemployed to support COVID-19 response efforts as recommended by GPEI (4). Surveillance staff and GPEI logistical assets supported COVID-19 surveillance, contact tracing, and data management. The virologic analyses of COVID-19 specimens increased the workload of GPLN staff, who often analyze specimens from multiple laboratory networks. During 2020, movement restrictions in many countries led to batching stool specimens and sewage samples before shipping to the national level (9). For countries with no internal WHOaccredited national polio laboratories, transport was further impeded by international travel restrictions.

The findings in this report are subject to at least three limitations. First, factors including security concerns and hard-toreach subpopulations could affect national and subnational AFP surveillance indicators and limit their interpretation. Second, high NPAFP rates do not necessarily indicate highly sensitive surveillance because some reported AFP cases might 
TABLE 2. Number of poliovirus isolates from stool specimens of persons with acute flaccid paralysis and timing of results, by World Health Organization region - worldwide, 2019 and $2020^{*}$

\begin{tabular}{|c|c|c|c|c|c|c|c|}
\hline \multirow[b]{2}{*}{ WHO region/Year } & \multirow[b]{2}{*}{ No. of specimens } & \multicolumn{3}{|c|}{ No. of poliovirus isolates } & \multirow{2}{*}{$\begin{array}{l}\text { \% Poliovirus } \\
\text { isolation results } \\
\text { on time** }\end{array}$} & \multirow{2}{*}{$\begin{array}{l}\% \text { ITD results } \\
\text { within } 7 \text { days of } \\
\text { receipt at } \\
\text { laboratory }\end{array}$} & \multirow{2}{*}{$\begin{array}{l}\% \text { ITD results } \\
\text { within } 60 \text { days of } \\
\text { paralysis onset }\end{array}$} \\
\hline & & Wild $^{\dagger}$ & Sabin $\$$ & cVDPVף & & & \\
\hline \multicolumn{8}{|l|}{ African Region } \\
\hline 2019 & 51,634 & 0 & 1,207 & 303 & 93 & 99 & 94 \\
\hline 2020 & 47,914 & 0 & 3314 & 530 & 91 & 91 & NA \\
\hline \multicolumn{8}{|l|}{ American Region } \\
\hline 2019 & 1,957 & 0 & 15 & 0 & 80 & 78 & 88 \\
\hline 2020 & 1,066 & 0 & 12 & 0 & 81 & 82 & 82 \\
\hline \multicolumn{8}{|c|}{ Eastern Mediterranean Region } \\
\hline 2019 & 58,924 & 312 & 1,927 & 50 & 92 & 99 & 92 \\
\hline 2020 & 40,179 & 245 & 1,311 & 533 & 96 & 61 & 95 \\
\hline \multicolumn{8}{|l|}{ European Region } \\
\hline 2019 & 3,295 & 0 & 52 & 0 & 83 & 100 & 87 \\
\hline 2020 & 2,016 & 0 & 24 & 2 & 89 & 73 & 82 \\
\hline \multicolumn{8}{|c|}{ South-East Asia Region } \\
\hline 2019 & 88,734 & 0 & 1,807 & 10 & 94 & 98 & 97 \\
\hline 2020 & 44,799 & 0 & 1,315 & 0 & 94 & 95 & 90 \\
\hline \multicolumn{8}{|c|}{ Western Pacific Region } \\
\hline 2019 & 14,505 & 0 & 164 & 74 & 97 & 96 & 71 \\
\hline 2020 & 11,608 & 0 & 124 & 2 & 96 & 100 & 84 \\
\hline \multicolumn{8}{|l|}{ Total $\S^{\S}$} \\
\hline 2019 & 219,049 & 312 & 5,172 & 437 & 95 & 99 & 96 \\
\hline 2020 & 147,582 & 245 & 6,100 & 1,067 & 94 & 84 & 92 \\
\hline
\end{tabular}

Abbreviations: AFP = acute flaccid paralysis; $\mathrm{CVDPV}=$ circulating vaccine-derived poliovirus; ITD = intratypic differentiation; NA = not available; WHO = World Health Organization.

* 2019 data as of March 18, 2020; 2020 data as of March 25, 2021.

+ Number of AFP cases with WPV isolates.

$\S$ Either 1) concordant Sabin-like results in ITD test and VDPV screening, or 2 ) $\leq 1 \%$ VP1 nucleotide sequence difference compared with Sabin vaccine virus ( $\leq 0.6 \%$ for type 2).

9 For poliovirus types 1 and 3,10 or more VP1 nucleotide differences from the respective poliovirus; for poliovirus type 2, six or more VP1 nucleotide differences from Sabin type 2 poliovirus.

** Results reported within 14 days of receipt of specimen.

${ }^{+\dagger}$ Results of ITD reported within 7 days of receipt of specimen.

$\S \S$ For the last three indicators, total represents weighted mean percentage of regional performance.

not meet the case definition, some actual AFP cases might go undetected, and apparent adequate national data can obscure wide heterogeneity in subnational AFP rates. Finally, the accuracy of stool specimen collection timeliness depends on whether the field investigator can elicit an accurate paralysis onset date.

Sensitive AFP surveillance is critical to detecting poliovirus transmission and relies on timely case detection, notification, investigation, specimen transport, and laboratory testing. With adherence to proper infection control precautions, activities to restore sensitive surveillance must be pursued. Given the successful repurposing of polio resources to support COVID-19 pandemic challenges, further investments in disease surveillance could enable the program to respond to new threats. Thoughtful and planned action is needed as country Expanded Programmes on Immunization move to integrate surveillance for vaccine-preventable and other diseases.

\section{Summary}

What is already known about this topic?

Global polio eradication relies on detecting poliovirus transmission, primarily through acute flaccid paralysis (AFP) surveillance supplemented by environmental surveillance of sewage samples.

What is added by this report?

Analysis of 2019-2020 AFP surveillance data from 42 countries at high risk for poliovirus transmission indicated that national and subnational nonpolio AFP rates and stool specimen adequacy declined in many priority countries.

What are the implications for public health practice?

The findings provided in this report can help guide improvement efforts to restore timely and sensitive field surveillance activities, which were adversely affected by the COVID-19 pandemic. 


\section{Acknowledgments}

The Global Polio Eradication Initiative; The Global Polio Laboratory Network; Data and Information Management Network; Surveillance Task Team members; Ana Chevez; Eugene Saxentoff; Gloria Rey; Hieronyma Nelisiwe Gumede-Moeletsi; Humayun Asghar; Johnson Muluh Ticha; Lucky Sangal; Muhammad Obaid-ul Butt; Patrick Michael O'Connor; Shahin Huseynov; Sudhir Joshi; Tigran Avagyan; Varja Grabovac; Jane Iber; Elizabeth Henderson.

Corresponding author: Jude Tuma, Tuma@who.int, +41-76-560-7473.

${ }^{1}$ Polio Eradication Department, World Health Organization, Geneva, Switzerland; ${ }^{2}$ Global Immunization Division, Center for Global Health, CDC; ${ }^{3}$ Division of Viral Diseases, National Center for Immunization and Respiratory Diseases, CDC.

All authors have completed and submitted the International Committee of Medical Journal Editors form for disclosure of potential conflicts of interest. No potential conflicts of interest were disclosed.

\section{References}

1. Chard AN, Datta SD, Tallis G, et al. Progress toward polio eradicationworldwide, January 2018-March 2020. MMWR Morb Mortal Wkly Rep 2020;69:784-9. PMID:32584798 https://doi.org/10.15585/mmwr. mm6925a4

2. Alleman MM, Jorba J, Greene SA, et al. Update on vaccine-derived poliovirus outbreaks_-worldwide, July 2019-February 2020. MMWR Morb Mortal Wkly Rep 2020;69:489-95. PMID:32324719 https://doi. org/10.15585/mmwr.mm6916a1
3. World Health Organization. WHO Director-General's statement on IHR Emergency Committee on Novel Coronavirus (2019-nCoV). Geneva, Switzerland: World Health Organization; 2020. https://www.who.int/ director-general/speeches/detail/who-director-general-s-statement-onihr-emergency-committee-on-novel-coronavirus-(2019-ncov)

4. Global Polio Eradication Initiative. Polio oversight board meeting summary. Geneva, Switzerland: Global Polio Eradication Initiative; 2020. https://polioeradication.org/wp-content/uploads/2020/04/POB-meetingsummary-20200324.pdf

5. Lickness JS, Gardner T, Diop OM, et al. Surveillance to track progress toward polio eradication-worldwide, 2018-2019. MMWR Morb Mortal Wkly Rep 2020;69:623-9. PMID:32437342 https://doi.org/10.15585/ mmwr.mm6920a3

6. Asghar H, Diop OM, Weldegebriel G, et al. Environmental surveillance for polioviruses in the Global Polio Eradication Initiative. J Infect Dis 2014;210(Suppl 1):S294-303. PMID:25316848 https://doi.org/10.1093/ infdis/jiu384

7. Hsu CH, Rehman MS, Bullard K, et al. Progress toward poliomyelitis eradication-Pakistan, January 2019-September 2020. MMWR Morb Mortal Wkly Rep 2020;69:1748-52. PMID:33211676 https://doi. org/10.15585/mmwr.mm6946a5

8. Diop OM, Kew OM, de Gourville EM, Pallansch MA. The Global Polio Laboratory Network as a platform for the viral vaccine-preventable and emerging diseases laboratory networks. J Infect Dis 2017;216(Suppl 1):S299-307. PMID:28838192 https://doi.org/10.1093/ infdis/jix092

9. Zomahoun DJ, Burman AL, Snider CJ, et al. Impact of COVID-19 pandemic on global poliovirus surveillance. MMWR Morb Mortal Wkly Rep 2021;69:1648-52. PMID:33382673 https://doi.org/10.15585/ mmwr.mm695152a4 